Copyright (C) 2021 University of Bucharest Printed in Romania. All rights reserved

ISSN print: $1224-5984$

ISSN online: $2248-3942$
Rom Biotechnol Lett. 2021; 26(3): 2631-2639 doi: $10.25083 / \mathrm{rbl} / 26.3 / 2631-2639$

Received for publication, February, 10, 2020

Accepted, January, 8, 2021

Original paper

\title{
Arbuscular mycorrhizae colonization dynamic in Iris pseudacorus L. during second year after inoculation and planting in field
}

\section{IOANA CRIȘAN ${ }^{1}$, ROXANA VIDICAN ${ }^{1}$, ADRIANA MOREA ${ }^{1 *}$, VIORICA LAGUNOVSCHI ${ }^{2}$}

${ }^{1}$ University of Agricultural Sciences and Veterinary Medicine Cluj-Napoca, Romania

${ }^{2}$ University of Agronomic Sciences and Veterinary Medicine Bucharest, Romania

\begin{abstract}
In the last few years was observed an unprecedented market expansion of microbial inoculants for agriculture and environmental applications. Fungi from the phylum Glomeromycota can establish symbiosis with roots of more than $70 \%$ vascular plant species, ensuring enhanced nutrient uptake. Aim of this study was to assess functional integration of inoculated arbuscular mycorrhiza and implications for success of symbiose in field conditions and host fitness. Iris pseudacorus was used as perennial model plant for study of seasonal continuity and persisting effects in second year after inoculation. During 2019 was conducted Trouvelot microscopic evaluation for 1080 stained root samples and parameters were obtained using Mycocalc. Results showed that colonization was significantly influenced by phenophase. Inoculated plants presented values with $1.56-14.49 \%$ higher. Plant height correlated significantly positive with inoculation $\left(\mathrm{r}=0.336^{*}\right)$. Results showed that colonization parameters are useful indicators in tracking symbiose across a temporal gradient.
\end{abstract}

Keywords Rhizosphere, fungi, microbiome, soil, bioproducts, phytoremediation.

To cite this article: CRIȘAN I, VIDICAN R, MOREA A, LAGUNOVSCHI V. Arbuscular mycorrhizae colonization dynamic in Iris pseudacorus L. during second year after inoculation and planting in field. Rom Biotechnol Lett. 2021; 26(3): 2631-2639. DOI: $10.25083 / \mathrm{rbl} / 26.3 / 2631-2639$

ADRIANA MOREA, Department of Plant Culture, Faculty of Agriculture, University of Agricultural Sciences and Veterinary Medicine Cluj-Napoca, Manastur Street No. 3-5, 400372, Romania, Tel.: +40740650393

E-mail: adriana.morea@usamvcluj.ro 


\section{Introduction}

Arbuscular mycorrhizal symbiosis is a mutualistic relationship between plant roots and fungi from phylum Glomeromycota (BONFANTE et GENRE, 2018) with estimated $72 \%$ of vascular plants able to establish this positive interaction (BRUNDRETT et TEDERSOO, 2018). Although plants can survive in absence of fungal symbiont by contrast endomycorrhizal fungi are obligate biotrophs and thus unculturable in the absence of a living host (BONFANTE et GENRE, 2010).

In this partnership fungal symbiont ensures an enhanced flux of nutrients - particularly in phosphorus towards the plant and receives in exchange sugars and lipids from the host (KAFLE et al, 2019).

The life cycle of arbuscular mycorrhizae starts with spore germination. Fungal germling can recognize potential host by diffusible root exudates. In contact with root surface hyphae are forming the hyphopodium. Once the fungal hyphae enter the root the invagination of plant plasma membrane forms perifungal membrane which always surrounds intracellular structures of the mycobiont (BONFANTE et GENRE, 2010). Following the establishment of symbiosis, arbuscular mycorrhiza develops structures with functional roles inside and outside roots. Inside roots, hyphae continue to spread between cells, strictly from cell to cell or both, according to one of the eight distinct morphotypes which are host-dependent (DICKSON, 2004). Asexual spores form both inside and outside roots and vesicles acting as storage organs accumulate lipids (MÜLLER et al, 2017).

Fueled by a flux of carbon fixed through photosynthesis by the plant, arbuscular mycorrhizae fungi develop a network of extra-radicular hyphae which can spread up to $25 \mathrm{~cm}$ from the plant root into the soil harnessing nutrients (KAFLE et al, 2019). There is substantial evidence proving beneficial outcomes of this symbiose for plant development (CRIȘAN et al, 2017).

During last decade, the number of companies that produce and sell arbuscular mycorrhiza fungi inoculants have increased considerably, with over 70 companies active in Europe, one of the leading markets for the sector of microbial inoculants, with main domains of application in gardening and landscaping, horticulture and agriculture (CHEN et al, 2018).

Iris pseudacorus is a widely cultivated Mayflowering ornamental plant (CRIȘAN et al, 2018) with phytoremediation capacity (CALDELAS et al, 2005; WANG et al, 2013; ZHANG et al, 2017). Research shows that arbuscular mycorrhiza can enhance Iris pseudacorus tolerance to heavy metals (WĘŻOWICZ et al, 2015) and thus improving decontamination process.

Largest majority of research involving inoculation have been conducted in controlled environment, and there is a need for studies that could provide more insight related to symbiose behavior in real-life conditions. Also, has been little studied in the past the integration of commercial inoculants released into the environment.

Aim of the study was to obtain a description of root colonization dynamics following planting under field conditions and to assess functional integration of mycorrhizal inoculants with implications for success of symbiose and plant fitness. Objectives were:

- Obtaining descriptive parameters of endomycorrhizal colonization;

- Identification of arbuscular mycorrhiza continuity from one phenophase to another and one vegetative season to another;

- Prospecting the persisting effect of inoculation over colonization indicators and biologic characteristics of plants.

\section{Material and Methods}

The experiment was established in 2018 in AgroBotanical Garden UASVM Cluj-Napoca. In 2019, was performed analysis in order to evaluate continuity and dynamics of mycorrhizal colonization in field in second year since planting.

Iris pseudacorus plant material was purchased from company Anthesis International Bucharest and used at establishing a bifactorial experiment in pots. First factor represented by substrate type had two levels: commercial peat-based substrate (PE) and commercial bark humusbased substrate $(\mathrm{BH})$. Second factor represented by inoculation type had three levels: non-inoculated (0 AMF), inoculated with granular product "root grow ${ }^{\mathrm{TM}}$ mycorrhizal fungi" produced by Plantworks Ltd. U.K. and containing five Glomeromycota fungi species (5 AMF) and respectively inoculated with hydro-soluble product Aegis Irriga produced by Italpollina Italy, and containing two Glomeromycota fungi species (2 AMF).

Dose of application corresponded to instructions on label for both products. Presence of Glomeromycota spores in the products was confirmed under microscope (Figure 3a). From combination of the two factors, resulted six experimental variants (Table 1 ).

Table 1. Experimental variants

\begin{tabular}{|c|c|c|}
\hline Var. & Substrate & Mycorrhiza \\
\hline V1 & PE & \multirow{2}{*}{ 0 AMF } \\
\cline { 1 - 2 } V2 & BH & \\
\hline V3 & PE & 5 AMF \\
\cline { 1 - 2 } V4 & BH & \\
\hline V5 & PE & \multirow{2}{*}{$2 \mathrm{AMF}$} \\
\cline { 1 - 2 } V6 & BH & \\
\hline
\end{tabular}

Plants developed in pots during 15 April - 15 July 2018 and then were transferred in field with whole root system and pot substrate (Figure 1a, 1b, 1c). 

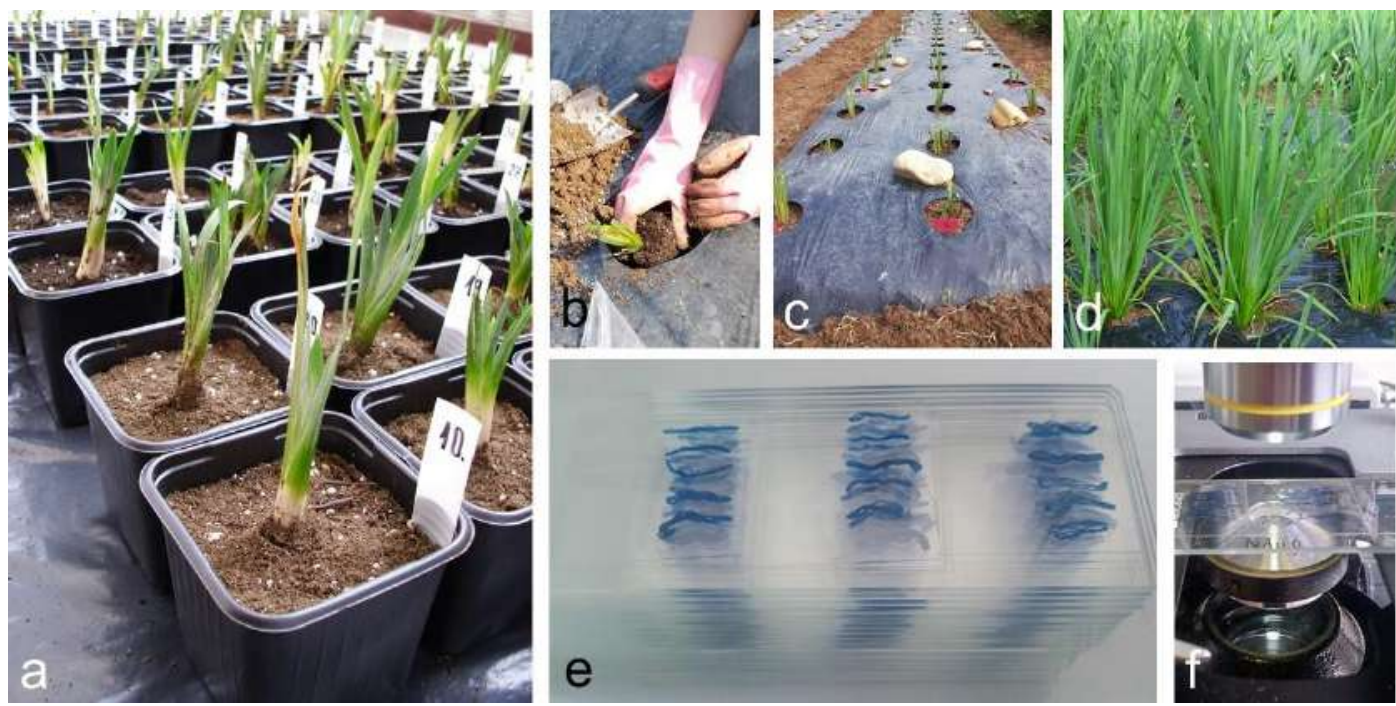

Figure 1. Experiment stages: a) plants in pots; b), c) plants transferred in field (2018); d) second vegetative season (2019); e) slides with stained root segments; f) microscopy.

Variants were organized in three randomized blocks with three replicates. Mulch foil was applied to minimize soil disturbance around plants. The soil in Agro-botanical Garden UASVM Cluj-Napoca where plot was located presents clay-loam texture, neutral $\mathrm{pH}$, low humus but good NPK content (CRIȘAN et al, 2019).

In 2019, corresponding to second vegetative season, root samples were collected for microscopic evaluation of endomycorrhizal colonization (Figure 1e, 1f). Sampling was conducted in July and October 2019 from field plot, when plants were in two distinct phenophases. At first sampling plants were entering relative summer resting signaled by ceasing growth while at second one plants were entering winter dormancy marked by debut of leaf senescence.

Roots were stained for microscopy using method by VIERHEILIG et al (1998), and evaluation was performed under Optika microscope at $200 \times$ following methodology by TROUVELOT et al (1986). In 2019, corresponding to second year of plant development in field, number of root samples analyzed was 1080 segments of $1 \mathrm{~cm}$ each: 30 roots $\times 3$ replicates $\times 6$ variants $\times 2$ samplings. Arbuscular mycorrhizal colonization parameters were obtained using Mycocalc software (https://www2.dijon. inra.fr/mychintec/):

- F\% = frequency of mycorrhizal colonization,

- $\mathrm{m} \%=$ intensity of the mycorrhizal colonization in the root fragments,

- $\mathrm{M} \%$ = intensity of the mycorrhizal colonization in the root system,

- $\mathrm{a} \%=$ abundance of exchange structures in mycorrhizal parts of root fragments,

- $\mathrm{A} \%=$ abundance of exchange structures in root system.

Biologic characteristics of plants were recorded at post-anthesis when plants stopped growth. Following characters were determined: plant height $(\mathrm{H})$, number of shoots $(\mathrm{H})$ and leaves $(\mathrm{L})$ per plant.
In order to identify the influence of colonization levels from previous year in the current year, were correlated mycorrhizal parameters from October 2018 (CRIȘAN et al, 2019) with those obtained in July 2019.

Statistical analysis performed was two-way ANOVA, Duncan test, Pearson correlation and partial correlation.

\section{Results}

Climatic conditions between planting in field and last sample collecting are presented in Figure 2. During this interval, high temperatures were registered in August 2018 after planting and in June-August of 2019.

Highest precipitation levels were registered in May 2019 when plants were in flowering phenophase, and low monthly sum of precipitation $\left(<20 \mathrm{~mm} / \mathrm{m}^{2}\right)$ was registered for November 2018, and during months of February and March 2019, prior to plants entering in vegetation.

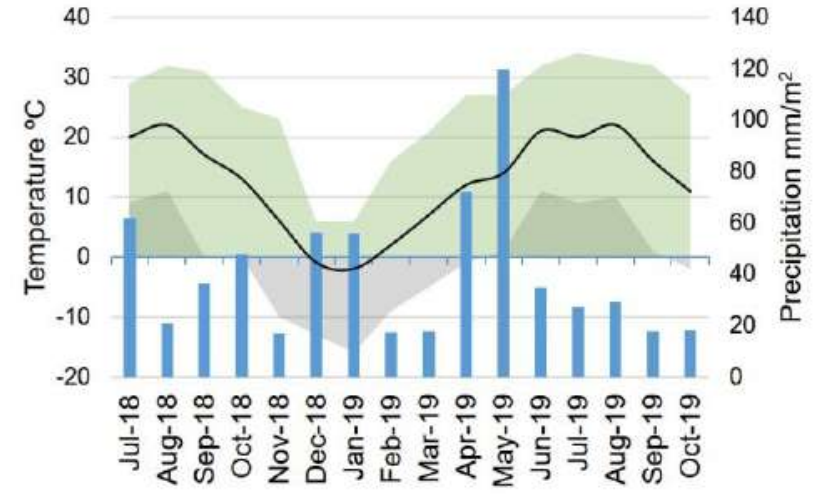

Min temp. $=$ Max temp. $=$ Precipitation - Average temp.

Figure 2. Climatic conditions during plant development in field (https://en.tutiempo.net/climate/, https://www.wunderground.com/history/monthly/ro/) 
Microscopic analysis of colonization pattern revealed that arbuscular mycorrhiza exhibits a typical Paris morphotype in Iris pseudacorus, with hyphae passing from cell-to cell without spreading through intercellular space (Figure 3).
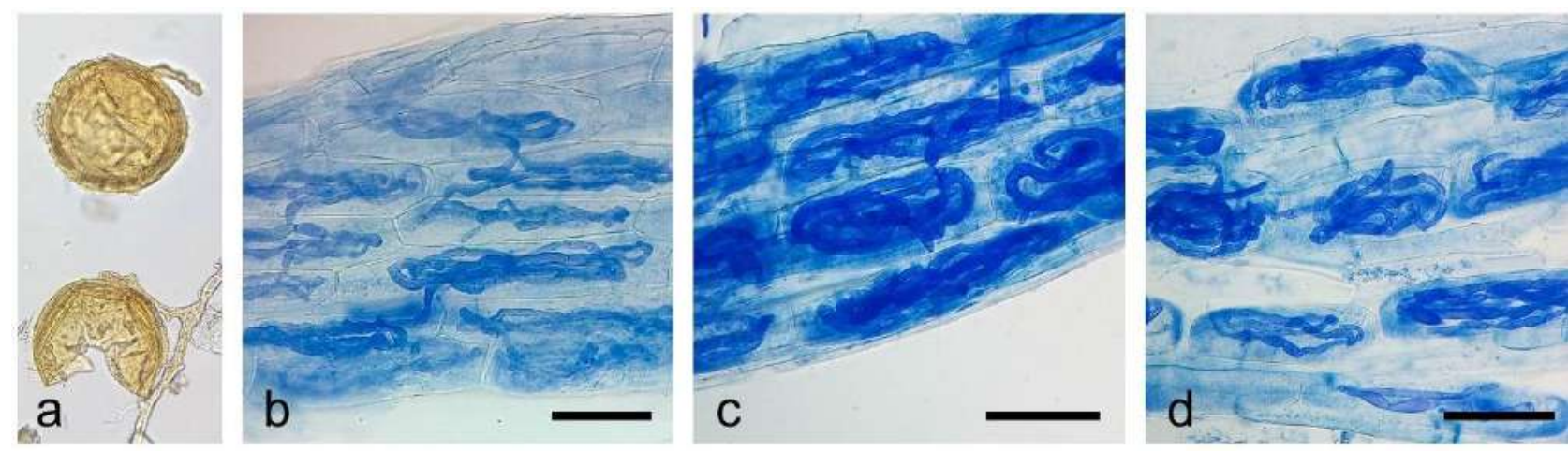

Figure 3. Arbuscular mycorrhiza a) Glomeraceae spores from inoculant 400x; b), c), d) root colonization displaying cell to cell spreading of hyphae: Paris morphotype in Iris pseudacorus stained roots; scale bar $=50 \mu \mathrm{m}$.

Analysis of variance indicates that phenophase exercised significant influence over all five colonization parameters. At the same time, in second vegetative season after inoculation, the treatment did not exercise significant influence on colonization, neither interaction between phenophase and inoculation (Table 2). Although not statistically significant, four out of five mycorrhizal colonization parameters presented higher values (Table 3).

Table 2. Influence of phenophase and treatment on AM colonization indicators in second vegetative year after inoculation and planting in field (2019)

\begin{tabular}{|c|c|c|c|c|}
\hline $\mathbf{A M}$ & Factors and interaction & $F$ test & $p$ value & Significance \\
\hline \multirow{3}{*}{$\mathrm{F} \%$} & Phenophase (P) & 24.670 & $<0.001$ & $* * *$ \\
\hline & Inoculation (I) & 0.576 & 0.453 & n.s. \\
\hline & Interaction $(\mathrm{P} \times \mathrm{I})$ & 0.049 & 0.826 & n.s. \\
\hline \multirow{3}{*}{$\mathrm{m} \%$} & Phenophase $(\mathrm{P})$ & 17.630 & $<0.001$ & $* * *$ \\
\hline & Inoculation (I) & 0.198 & 0.659 & n.s. \\
\hline & Interaction $(\mathrm{P} \times \mathrm{I})$ & 0.591 & 0.447 & n.s. \\
\hline \multirow{3}{*}{$\mathrm{M} \%$} & Phenophase (P) & 21.144 & $<0.001$ & $* * *$ \\
\hline & Inoculation $(\mathrm{I})$ & 0.003 & 0.955 & n.s. \\
\hline & Interaction $(\mathrm{P} \times \mathrm{I})$ & 0.322 & 0.574 & n.s. \\
\hline \multirow{3}{*}{$\mathrm{a} \%$} & Phenophase $(\mathrm{P})$ & 12.204 & 0.002 & $* *$ \\
\hline & Inoculation (I) & 0.009 & 0.926 & n.s. \\
\hline & Interaction $(\mathrm{P} \times \mathrm{I})$ & 0.023 & 0.880 & n.s. \\
\hline \multirow{3}{*}{$\mathrm{A} \%$} & Phenophase $(\mathrm{P})$ & 11.206 & 0.002 & $* *$ \\
\hline & Inoculation (I) & 0.082 & 0.776 & n.s. \\
\hline & Interaction $(\mathrm{P} \times \mathrm{I})$ & 0.385 & 0.539 & n.s. \\
\hline
\end{tabular}

Two-way ANOVA; $>0.05$ (n.s.), $\mathrm{p}<0.05(*), \mathrm{p}<0.01(* *), \mathrm{p}<0.001(* * *)$

Table 3. Influence of treatment on colonization parameters, during second vegetative year (2019)

\begin{tabular}{|l|c|c|c|c|c|}
\hline \multicolumn{1}{|c|}{ Treatment } & $\mathbf{F \%}$ & $\mathbf{m \%}$ & $\mathbf{M \%}$ & $\mathbf{a \%}$ & $\mathbf{A \%}$ \\
\hline Non inoculated & $49.72 \pm 7.49$ & $6.37 \pm 1.31$ & $3.86 \pm 0.93$ & $18.30 \pm 3.71$ & $1.06 \pm 0.36$ \\
\hline Inoculated & $45.42 \pm 3.76$ & $7.14 \pm 1.40$ & $3.92 \pm 0.87$ & $18.75 \pm 3.47$ & $1.21 \pm 0.40$ \\
\hline Variance $\left(\mathrm{s}^{2}\right)$ & 438.68 & 37.54 & 15.23 & 241.38 & 3.04 \\
\hline
\end{tabular}

\pm standard error of mean 
Thus, plants inoculated in previous year showed $12.05 \%$ higher intensity of colonization in mycorrhized root fragments $(\mathrm{m} \%)$, and $1.56 \%$ higher colonization intensity in root system (M\%) in 2019. Similarly, both abundance of exchange structures in mycorrhized parts of root fragments $(\mathrm{a} \%)$ and root system $(\mathrm{A} \%)$ presented increased values with $2.43 \%$ and $14.49 \%$ respectively, relative to non-inoculated variants.

Results showed a decreasing trend for all colonization parameters towards autumn (Figure 4). Frequency of colonization decreased with $45.73 \%$ at entering in winter dormancy relative to summer, intensity of colonization in mycorrhized root fragments decreased with $71.71 \%$, intensity of endomycorrhizal colonization in root system decreased with $79.34 \%$, abundance of exchange structures in mycorrhizal parts for root fragments decreased with $62.62 \%$ and abundance of exchange structures in root system decreased with $90.13 \%$.

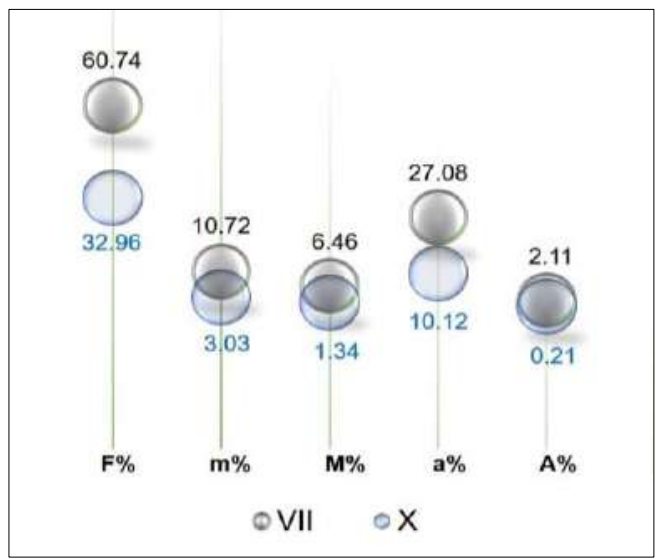

Figure 4. Influence of phenophase on colonization indicators, VII (July) and X (October) 2019.

Analysis of the influence of phenophase and experimental variant on frequency and intensity of colonization demonstrated there is no significant difference among variants in summer neither among variants in autumn for these parameters (Figure 5, Figure 6). However, four variants (V1, V3, V5, V6) present a significant difference for frequency of colonization between phenophases (Figure 5), and one variant (V6) presents significant differences between phenophases for intensity of colonization as well (Figure 6). These variants correspond both to plants which were inoculated as well as plants which were not inoculated prior to planting.

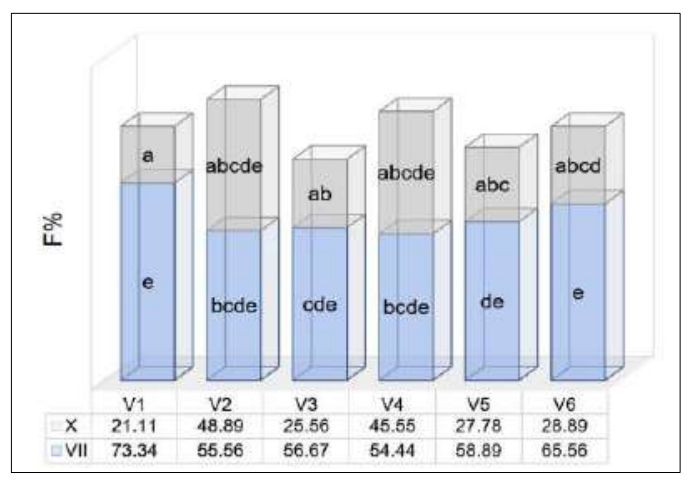

Figure 5. Influence of phenophase and experimental variant on colonization frequency, (VII) July and (X) October 2019; differences between values with at least one common letter are n.s., $\mathrm{p}<0.05$.

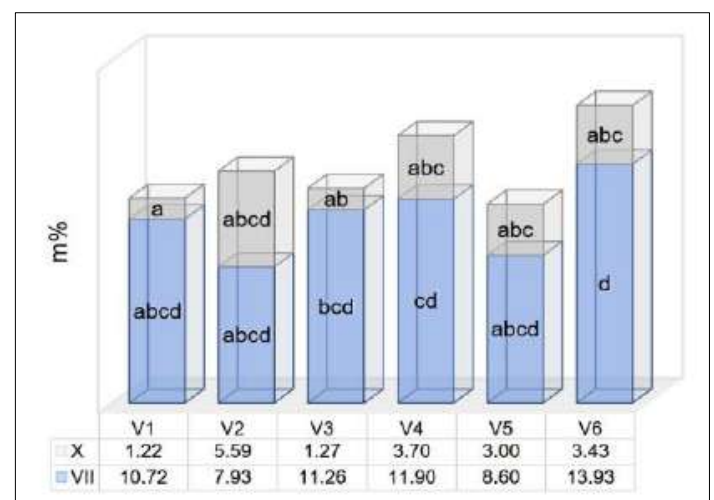

Figure 6. Influence of phenophase and experimental variant on colonization intensity of root fragments, (VII) July and (X) October 2019; differences between values with at least one common letter are n.s., $p<0.05$.

Average endomycorrhizal colonization parameters during 2019 presented variation in value among variants (Table 4). In order to identify the mycorrhizal pattern and differences related to symbiotic endo-development between phenophases, Pearson correlations were analyzed between colonization parameters (Table 5).

Table 4. Influence of experimental variant on endomycorrhizal colonization parameters in Iris pseudacorus (2019)

\begin{tabular}{|c|c|c|c|c|c|}
\hline Var. & $\mathbf{F \%}$ & $\mathbf{m \%}$ & $\mathbf{M \%}$ & $\mathbf{a \%}$ & $\mathbf{A \%}$ \\
\hline V1 & $47.23 \pm 13.43$ & $5.97 \pm 2.26$ & $3.89 \pm 1.72$ & $17.96 \pm 6.45$ & $1.22 \pm 0.69$ \\
\hline V2 & $52.22 \pm 8.01$ & $6.76 \pm 1.53$ & $3.83 \pm 0.91$ & $18.65 \pm 4.35$ & $0.89 \pm 0.28$ \\
\hline V3 & $41.11 \pm 7.63$ & $6.27 \pm 3.30$ & $3.23 \pm 1.78$ & $14.07 \pm 5.96$ & $0.97 \pm 0.63$ \\
\hline V4 & $50.00 \pm 5.58$ & $7.80 \pm 2.76$ & $4.18 \pm 1.43$ & $11.53 \pm 2.26$ & $0.64 \pm 0.30$ \\
\hline V5 & $43.33 \pm 7.55$ & $5.80 \pm 2.48$ & $2.93 \pm 1.35$ & $19.68 \pm 5.33$ & $0.85 \pm 0.47$ \\
\hline V6 & $47.22 \pm 10.20$ & $8.68 \pm 3.23$ & $5.34 \pm 2.50$ & $29.71 \pm 10.63$ & $2.37 \pm 1.38$ \\
\hline
\end{tabular}

\pm standard error of mean 
Table 5. Relationship between endomycorrhizal colonization parameters in second year after inoculation and planting in field (2019)

\begin{tabular}{|c|c|c|c|c|c|c|c|}
\hline Month & Indicators & Var. & F\% & $\mathbf{m} \%$ & М\% & a\% & A\% \\
\hline \multirow{6}{*}{$\begin{array}{l}\text { July } \\
2019\end{array}$} & Var. & - & -0.128 & 0.151 & 0.138 & 0.207 & 0.265 \\
\hline & $\mathrm{F} \%$ & -0.128 & - & -0.074 & 0.311 & 0.182 & 0.294 \\
\hline & $\mathrm{m} \%$ & 0.151 & -0.074 & - & $0.914 * * *$ & $0.562^{*}$ & $0.758 * * *$ \\
\hline & M\% & 0.138 & 0.311 & $0.914 * * *$ & - & $0.598 * *$ & $0.855^{* * * *}$ \\
\hline & $\mathrm{a} \%$ & 0.207 & 0.182 & $0.562^{*}$ & $0.598 * *$ & - & $0.886^{* * * *}$ \\
\hline & $\mathrm{A} \%$ & 0.265 & 0.294 & $0.758 * * *$ & $0.855^{* * *}$ & $0.886^{* * *}$ & - \\
\hline \multirow{6}{*}{$\begin{array}{l}\text { October } \\
2019\end{array}$} & Var. & - & -0.012 & 0.103 & 0.014 & 0.297 & -0.052 \\
\hline & $\mathrm{F} \%$ & -0.012 & - & $0.689 * *$ & $0.878 * * *$ & 0.373 & $0.793 * * *$ \\
\hline & $\mathrm{m} \%$ & 0.103 & $0.689 * *$ & - & $0.939 * * *$ & $0.586^{*}$ & $0.873^{* * *}$ \\
\hline & M\% & 0.014 & $0.878 * * *$ & $0.939 * * *$ & - & $0.534 *$ & $0.925 * * *$ \\
\hline & $\mathrm{a} \%$ & 0.297 & 0.373 & $0.586^{*}$ & $0.534^{*}$ & - & $0.669 * *$ \\
\hline & $\mathrm{A} \%$ & -0.052 & $0.793 * * *$ & $0.873 * * *$ & $0.925^{* * *}$ & $0.669 * *$ & - \\
\hline
\end{tabular}

Pearson correlation; $p<0.05(*), p<0.01(* *), p<0.001(* * *)$

In July 2019 was identified a highly significant positive correlation between intensity of colonization in mycorrhizal fragments $(\mathrm{m} \%)$ and two other parameters: intensity of colonization in root system and abundance of exchange structures in root system. This relationship remains unchanged until autumn, reflected by similar significance of these correlations in July and October 2019. Similarly, the significant correlation between mycorrhizal intensity and abundance of exchange structures in colonized root fragments maintains at the same level of significance in the two phenophases. Several other correlations remain significant between the two phenophases such as correlation between intensity of colonization in root system and the two parameters of abundance of exchange structures. The correlation between the abundance of exchange structures parameters remains significantly positive but the coefficient value presents a decrease in autumn compared to summer. Differences regarding the relationship between the two phenophases occur for correlations between frequency of colonization and the other colonization parameters, neither which is significant in summer. By contrast, in autumn frequency of colonization correlates highly positive with intensity of colonization in root system as well as with abundance of exchange structures in root system. In 2019 at post-anthesis when plants ceased growth, Iris pseudacorus presented an average number of shoots per plant between 5.56-6.50, average number of leaves per plant between 29.33-35.67 and an average height of 75.83-92.78 cm (Figure 7). Differences between biologic characteristics of plants are not significant in second year after treatment.
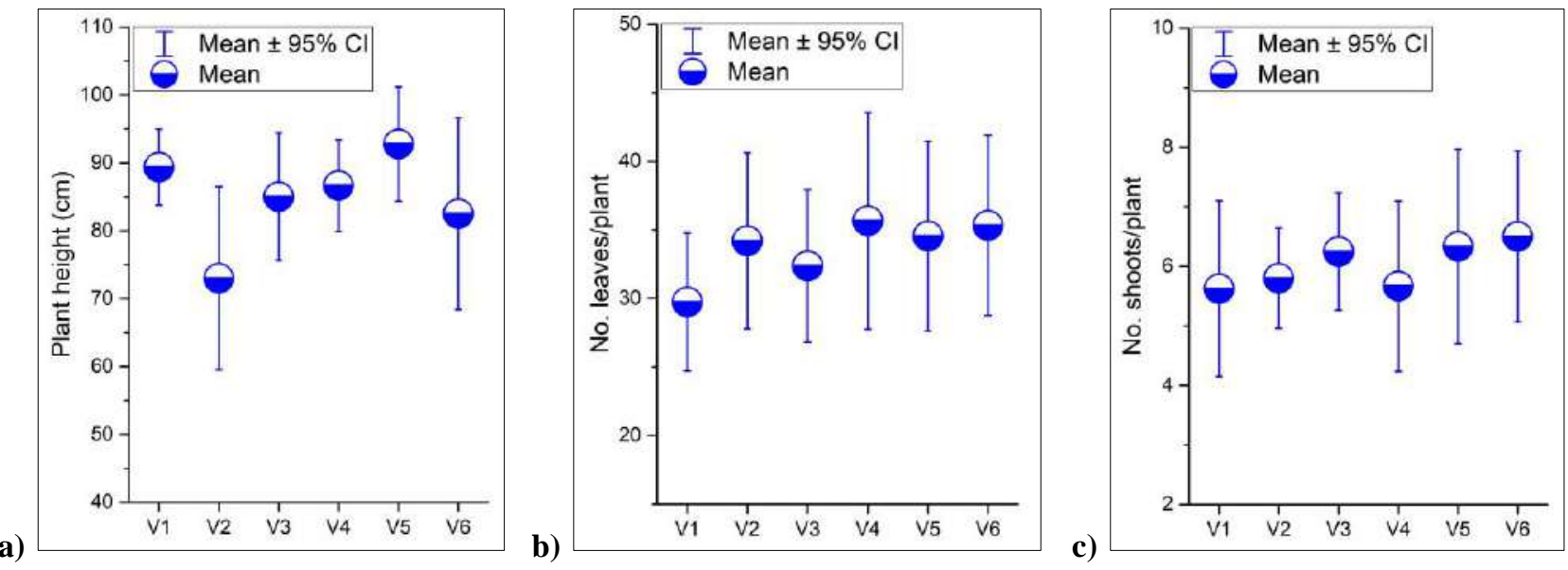

Figure 7. Biologic characteristics of Iris pseudacorus plants in 2019,

a) plant height, b) number of leaves per plant, c) number of shoots per plant. 
Since it is essential to identify if there was any lasting effect that inoculation could have had on plants in field, were comparatively analyzed simple linear and partial correlation coefficients between inoculation treatment and plant characteristics (Figure 8a, Figure 8b).
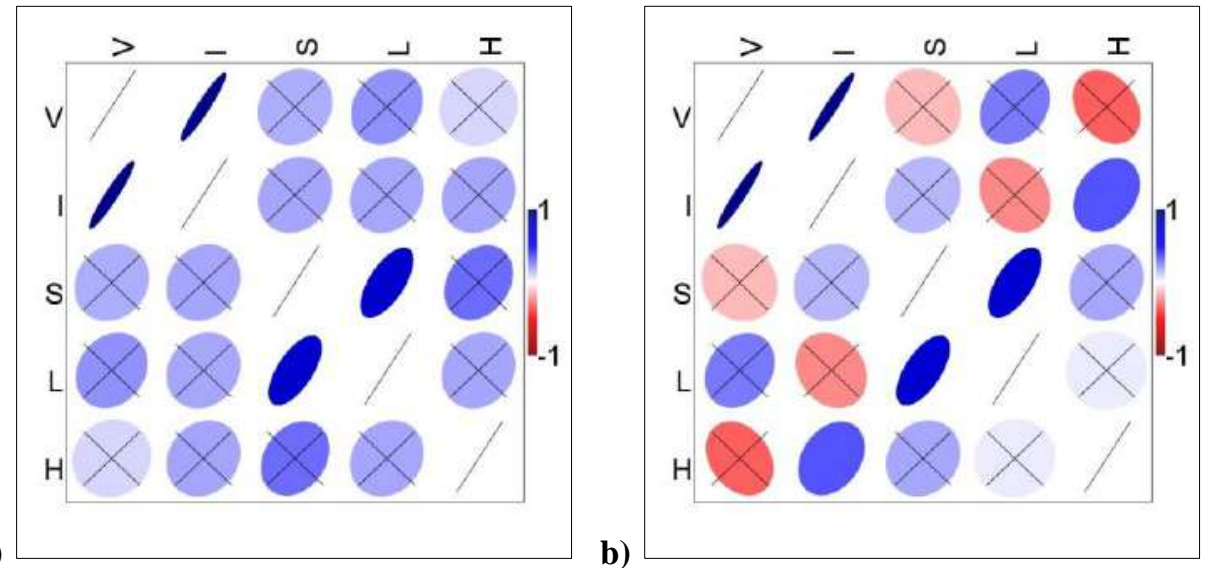

Figure 8. Influence of treatment on biologic characteristics of Iris pseudacorus plants in 2019 (a) simple linear and (b) partial correlograms, where: V- variant gradient, I- inoculation, H- plant height $(\mathrm{cm})$, L- number of leaves and S- number of shoots per plant; crossed $\mathrm{p}>0.05$ (n.s.).

By applying partial correlation, was identified a significantly positive correlation between inoculation treatment performed in previous year and plant height in new vegetative year $\left(\mathrm{r}=0.336^{*}\right)$. Interestingly, through simple linear correlation this relationship cannot be put in evidence $(r=0.175)$ because plant height is positively correlated with other plant characteristics such as number of shoots per plant, and only by canceling their influence this relationship can be observed.

In order to reconstruct the overall mycorrhizal persistence and development from one year to the next, partial correlations were analyzed between colonization parameters from October 2018 and colonization parameters from July 2019 (Figure 9).

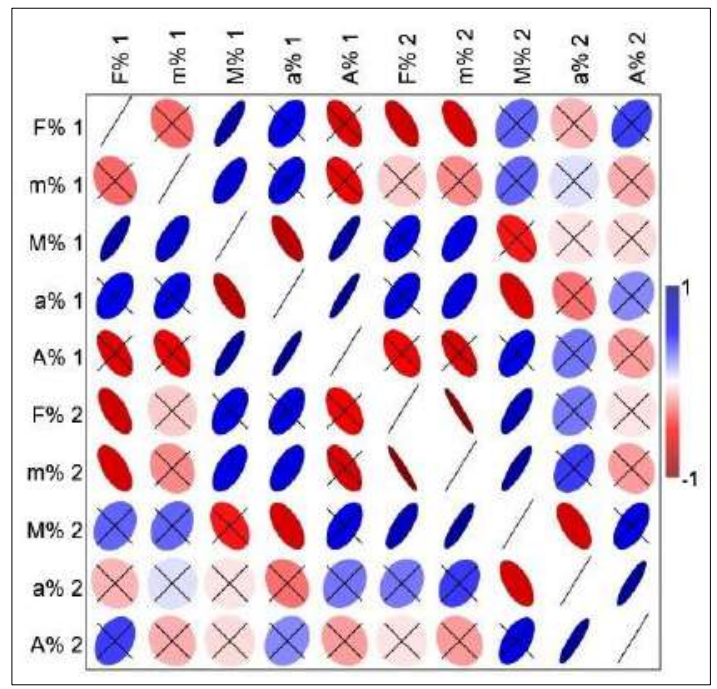

Figure 9. Partial correlation matrix for colonization parameters between autumn 2018 (1) and summer 2019 (2), crossed $p>0.05$ (n.s.).
This was meant to find if root colonization levels at the end of vegetative season can influence the parameters from next growing season. Results show that intensity of colonization of mycorrhizal root fragments in 2019 (m\% 2) is influenced significantly positive by two parameters from the previous year: intensity of colonization in root system (M\% 1) with $\mathrm{r}=0.640 * *$ and respectively abundance of exchange structures in mycorrhizal parts of roots fragments (a\% 1) with $\mathrm{r}=0.654 * *$.

\section{Discussion}

Phenophase exercised significant influence on all colonization parameters, which demonstrates the strong control of the host plant metabolism over the symbiose.

Thus, while climatic conditions, particularly temperature controls Iris plant phenology (CRIȘAN et al, 2016) in turn the plant metabolic state further controls arbuscular mycorrhizae symbiose.

All colonization parameters presented higher values in summer and decreased towards autumn. A study conducted in a tallgrass prairie ecosystem identified similarly the existence of a seasonal variation in endomycorrhizal colonization, with significant influence of the month of collecting samples, and higher levels of colonization were registered in mid-late summer (MANDYAM et JUMPPONEN, 2008).

The decrease in value of correlation coefficient between the two parameters of exchange structures abundance in autumn compared to summer is indicating the decline of symbiotic interface at the end of vegetative season. This could be triggered by leaf senescence which translates in reduction of photosynthetic capacity (CRIȘAN et al, 2016) and thus reduction of carbon influx towards mycobiont. At the same time, the fact that highly significant 
correlation between frequency of colonization and intensity as well as abundance of exchange structures in root system were observed only in autumn, this could indicate the shift towards an endophytic, latent phase.

Arbuscular mycorrhizae root colonization morphotype identified in Iris pseudacorus, corresponds to Paris type on scale by DICKSON (2004) with more or less dense intra-cellular hyphae coils representing the exchange interface for nutrients between symbionts. Similar morphotype was described before in Iris stolonifera (ZUBECK et al, 2011) which might be typical for this botanic genus yet researches on other species are necessary in order to establish this. Morphotype is primarily controlled by host plant. This was demonstrated by previous authors through isolation and inoculation of arbuscular mycorrhizal fungi which developed Paris-type in Hemerocallis but Arum-type in Zea mays. There are both anatomical and physiological reasons for occurrence of a specific morphotype in different plant species, but most important ones seem related to restrictiveness of intercellular spaces in host root and differences in plant cell wall structure. Although Paris type is more frequent in plant kingdom it has been less studied (SMITH et SMITH, 1997).

After planting in field, the roots of Iris pseudacorus were colonized by native arbuscular mycorrhizal fungi community from soil. Plants had a vigorous growth in second year having close to one meter in height. It is expected that roots of neighboring plants by the second year were very close to each other. But with all these, in second year were registered higher values in four out of five colonization parameters for inoculated plants. This could be attributed to propagules originating from fungi strains inoculated and surviving both in rhizosphere as well as inside roots during unfavorable period of the year. Common extra-radicular mycorrhizal networks can occur between rhizosphere of individual plants found in proximity of each other and colonized by Glomeromycota fungi, aspects that holds ecologic significance (NOVAIS et al, 2017). It would be interesting to study in the future mycorrhizal networks between inoculated and non-inoculated plants in field conditions.

Focus of the current research was colonization dynamics and mycorrhizal continuity. From this perspective, relationship pattern between colonization parameters from one phenophase to another and between vegetative years seems to indicate that arbuscular mycorrhiza might enter a latent root infection phase in autumn. Propagules could survive during winter dormancy of plants until next year inside roots and then recolonize the root system. This is suggested by significant dependency of colonization intensity in root fragments during new vegetative season of two mycorrhizal parameters registered in autumn of previous year indicating to a mycorrhizal continuity in rhizosphere. This suggests the persistent influence mycorrhizal inoculants could have once dispersed into environment.

\section{Conclusion}

There is a growing market segment dedicated to microbial inoculants because they present a great opportunity to harness ecosystem services to achieve desirable results while minimizing inputs.

In this research conducted on Iris pseudacorus during second year after inoculation and planting in field was identified that all plants were colonized and displayed Paris morphotype, but those inoculated in previous year presented higher values compared to non-inoculated ones, with up to $14.49 \%$ relative to non-inoculated prior to planting in field.

Phenophase exercises significant influence over all colonization parameters: frequency, intensity and abundance of exchange structures.

Results indicate that inoculation can have lasting influence on colonization in field conditions and plant biologic characteristics.

\section{Conflict of Interest}

The authors have no conflict of interest to declare.

\section{References}

1. BONFANTE P, GENRE A. Mechanisms underlying beneficial plant - fungus interactions in mycorrhizal symbiosis. Nat. Commun 2010: 48; doi: 10.1038/ ncomms 1046

2. BRUNDRETT MC, TEDERSOO L. Evolutionary history of mycorrhizal symbioses and global host plant diversity, New Phytol. 2018; 220: 1108-1115. doi:10.1111/nph.14976

3. CALDELAS C, ARAUS JL, FEBRERO A, BORT J. Accumulation and toxic effects of chromium and zinc in Iris pseudacorus L. Acta Physiol. Plant. 2005; 34: 1217-1228. doi: 10.1007/s11738-012-0956-4

4. CHEN M, ARATO M, BORGHI L, NOURI E et al. Beneficial services of arbuscular mycorrhizal fungi from ecology to application. Front. Plant Sci. 2018; 20189: 1270. doi: 10.3389/fpls.2018.01270

5. CRIȘAN I, STOIE A, CANTOR M. Overwintering of some hardy Iris species in Agro-botanical Garden UASVM Cluj-Napoca. Agriculture Science and Practice 2016; 3-4: 6-14. doi: 10.15835/agrisp.v99i34.12670

6. CRIȘAN I, VIDICAN R, STOIAN V. Utilization of arbuscular mycorrhizae in the cultivation of ornamental plants. Research Journal of Agricultural Science 2017; 49(4): 392-397.

7. CRIȘAN I, STOIE A, BUTA E, CANTOR M. Flowering phenology of some Iris species in the UASVM Cluj Agrobotanical Garden. Rom. Biotech. Lett. 2018; 23(3): 13702-13707. 
8. CRIŞAN I, VIDICAN R, STOIAN V, VÂTCĂ S, Prospecting the influence of potting substrate and AM inoculation on Iris pseudacorus L. Scientific Papers. Series A. Agronomy 2019; 62(2): 128-134.

9. DICKSON S, The Arum-Paris continuum of mycorrhizal symbioses. New Phytol. 2004; 163(1): 187-200. doi: 10.1111/j.1469-8137.2004.01095.x

10. KAFLE A, COPE KR, RATHS R, KRISHNA YJ et al. Harnessing soil microbes to improve plant phosphate efficiency in cropping systems. Agronomy 2019; 9: 127. doi: 10.3390 /agronomy 9030127

11. MANDYAM K, JUMPPONEN A. Seasonal and temporal dynamics of arbuscular mycorrhizal and dark septate endophytic fungi in a tallgrass prairie ecosystem are minimally affected by nitrogen enrichment. Mycorrhiza 2008; 18(3): 145-155. doi: 10.1007/ s00572-008-0165-6.

12. MÜLLER A, BENARD N, EDGAR P, ECKHARD G. Quantity and distribution of arbuscular mycorrhizal fungal storage organs within dead roots. Mycorrhiza. 2017; 27(3): 201-210. doi: 10.1007/s00572-0160741-0

13. NOVAIS CB, PEPE A, SIQUEIRA JO, GIOVANNETTI $M$ et al. Compatibility and incompatibility in hyphal anastomosis of arbuscular mycorrhizal fungi. Sci. agric. (Piracicaba, Braz.) 2017; 74(5): 411-416. doi: 10.1590/1678-992x-2016-0243

14. SMITH FA, SMITH SE. Structural diversity in (vesicular)-arbuscular mycorrhizal symbioses. New Phythol. 1997; 137: 373-388. doi: 10.1046/j.14698137.1997.00848.x

15. TROUVELOT A, KOUGH JL, GIANINAZZIPEARSON V, V. GIANINAZZI-PEARSON and S. GIANINAZZI (eds.). Mesure du taux de mycorhization VA d'un système radiculaire. Recherche de méthodes d'estimation ayant une signification fonctionnelle. In: Physiological and Genetical Aspects of
Mycorrhizae. INRA Press, Paris 1986; pp. 217-221.

16. VIERHEILIG H, COUGHLAN AP, WYSS U, PICHÉ Y. Ink and vinegar, a simple staining technique for arbuscular-mycorrhizal fungi. Appl Environ Microbiol. 1998; 64(12): 5004-5007.

17. WANG Q, YANG J, LI C, XIAO B et al. Influence of initial pesticide concentrations in water on chlorpyrifos toxicity and removal by Iris pseudacorus. Water Sci. Technol. 2013; 67(9): 1908-1915. doi: 10.2166/ wst.2013.071.

18. WANG YN, CHENG LJ, ZHOU QX. Phytoremediation of petroleum contaminated soils with Iris pseudacorus L. and the metabolic analysis in roots. Huan Jing Ke Xue. 2016; 37(4): 1531- 1538.

19. WEZOWICZ K, TURNAU K, ANIELSKA T, ZHEBRAK I et al. Metal toxicity differently affects the Iris pseudacorus-arbuscular mycorrhiza fungi symbiosis in terrestrial and semi-aquatic habitats. Environ. Sci. Pollut. Res. Int. 2015; 22: 19400-19407. doi: 10.1007/s11356-015-5706-X

20. ZHANG XB, LIU P, YANG YS, CHEN WR. Phytoremediation of urban wastewater by model wetlands with ornamental hydrophytes. J. Environ. Sci. 2017; 19(8), 902-909.

21. ZUBEK S, NOBIS M, BLASZKOWSKI J, MLECZKO $\mathrm{P}$ et al. Fungal root endophyte associations of plants endemic to the Pamir Alay Mountains of Central Asia. Symbiosis 2011; 54(3): 139-149. doi: 10.1007/s13199-011-0137-z

22. https://www2.dijon.inra.fr/mychintec/Mycocalc-prg/ download.html Accessed 28 January 2020

23. https://en.tutiempo.net/climate/ws-151200.html, Accessed 28 January 2020

24. https://www.wunderground.com/history/monthly/ro/ cluj-napoca/LRCL Accessed 28 January 2020 